\title{
Neonatal outcomes with caesarean delivery at term
}

\author{
F A Liston, ${ }^{1,2}$ V M Allen, ${ }^{1}$ C M O'Connell, ${ }^{3}$ K A Jangaard ${ }^{2}$
}

\section{See Perspective, p F174}

${ }^{1}$ Department of Obstetrics and Gynaecology, Dalhousie University, Halifax, Nova Scotia, Canada; ${ }^{2}$ Department of Paediatrics, Dalhousie University, Halifax, Nova Scotia, Canada; ${ }^{3}$ Department of Perinatal Epidemiology, Research Unit, Dalhousie University, Halifax, Nova Scotia, Canada

Correspondence to:

Dr K A Jangaard, Division of Neonatal-Perinatal Medicine, Department of Paediatrics, 5850/5980 University Avenue, Halifax, Nova Scotia, Halifax,

Nova Scotia, Canada B3K 6R8 krista.jangaard@dal.ca

Accepted 10 October 2007

Published Online First

17 October 2007

\section{ABSTRACT}

Objective: To estimate the impact of caesarean delivery on the incidence of selected neonatal outcomes.

Patients and methods: A 15-year, population-based, cohort study (1988-2002) using the Nova Scotia Atlee Perinatal Database compared neonatal outcomes in term newborns born by spontaneous and assisted vaginal delivery, with newborns born by caesarean delivery, with and without labour, using multiple logistic regression.

Results: From a total of 142929 deliveries, there were 27263 caesarean deliveries, 61\% of which were performed in labour. Relative risks were adjusted for year of birth, maternal age, parity, smoking, maternal weight at delivery, hypertensive diseases, diabetes, previous caesarean delivery, use of regional anaesthesia, induction of labour, gestational age at delivery and large and small for gestational age, where significant. Caesarean delivery in labour, but not caesarean delivery without labour, had increased risks for depression at birth and neonatal respiratory conditions compared with spontaneous or assisted vaginal delivery. Compared with spontaneous vaginal delivery and assisted vaginal delivery, the risk of major neonatal birth trauma was decreased for infants after caesarean delivery with labour lodds ratio $(\mathrm{OR})=0.34,95 \% \mathrm{Cl} 0.21$ to 0.56 and $\mathrm{OR}=0.07,95 \% \mathrm{Cl}$ 0.04 to 0.11 , respectively) and caesarean delivery without labour $(\mathrm{OR}=0.20,95 \% \mathrm{Cl} 0.08$ to 0.52 and $\mathrm{OR}=0.04$, $95 \% \mathrm{Cl} 0.02$ to 0.10 , respectively).

Conclusion: Caesarean delivery in labour, compared with vaginal delivery, is more likely to be associated with an increased risk for respiratory conditions and depression at birth than caesarean delivery without labour. Caesarean delivery appears protective against neonatal birth trauma, especially when performed without labour.

Understanding the impact of method of delivery on neonatal morbidity and mortality becomes essential in the context of rising caesarean delivery rates in North America ${ }^{12}$ and world wide. ${ }^{3}$ These increasing rates have been explained in part by changing maternal characteristics ${ }^{4}$ and obstetric practice patterns, ${ }^{14}$ and by continued interest in "patient choice" caesarean delivery. ${ }^{56}$ Recent population-based determinations of outcomes by type of labour and by method of delivery have improved our understanding of the maternal risks with caesarean and operative vaginal delivery. ${ }^{7-10}$ Information on neonatal outcomes associated with method of delivery has focused on respiratory morbidity, ${ }^{11-17}$ and may have been influenced by gestational age at delivery, ${ }^{11}{ }^{18}$ and the presence of maternal complications ${ }^{11}$ or previous obstetric interventions. ${ }^{12} 1319$ Small study numbers and outcomes in select groups may limit the generalisability of these reported risks. ${ }^{13}{ }^{17}$ 19-21 Using data from a large population-based database, we examined neonatal morbidity outcomes by method of delivery in a large high- and low-risk population at term.

\section{PATIENTS AND METHODS}

This population-based, cohort analysis was performed using data from the Nova Scotia Atlee Perinatal Database from 1988 to 2002. The Nova Scotia Atlee Perinatal Database is a provincial, population-based computerised database that collects information on maternal characteristics, maternal medical conditions, obstetric procedures and pregnancy outcomes on all pregnancies and births in the province of Nova Scotia, which has about 10000 live births each year ${ }^{22}$ and a homogeneous, predominantly Caucasian population of approximately 1 million. ${ }^{23}$ Health records personnel collect the information from standardised patient care records, and all information is entered into the database soon after the time of collection. The Nova Scotia Atlee Perinatal Database is known to be comprehensive, reliable and of high quality.

All deliveries occurring to a resident of Nova Scotia between 1 January 1988 and 31 December 2002, which resulted in a live born singleton at term ( $\geqslant 36$ weeks) without any known major congenital anomalies, were included in the study. Preterm deliveries, multiple gestation and pregnancies complicated by congenital anomalies were excluded from the study population on the basis that the indications for caesarean delivery in this population may differ from those for the term population.

Neonatal outcomes that were examined included depression at birth, birth trauma, neonatal respiratory conditions, admission to the neonatal intensive care unit (NICU), and breast feeding at postpartum discharge. Depression at birth included delay in initiating and maintaining respiration (requirement for resuscitation by mask for greater than 3 minutes or resuscitation by tube for any length of time), 5 -minute Apgar score $\leqslant 3$, and evidence of hypoxic-ischaemic encephalopathy (HIE, Sarnat score $>$ stage 1$)^{24}$ or associated systemic (cardiac, renal, hepatic) sequelae. Birth trauma was defined as minor (cephalohaematoma) and major (one or a combination of any fracture, facial palsy, phrenic nerve palsy, Erb's palsy, Klumpke's palsy, spinal cord trauma, traumatic intracranial haemorrhage or intraventricular haemorrhage of grade III or IV). Neonatal respiratory conditions included moderate or severe infant respiratory distress syndrome (RDS), transient tachypnoea of the newborn (TTN), and aspiration pneumonitis. NICU admission was included if the neonatal stay was greater than 24 hours. Cord arterial $\mathrm{pH}$ and base excess values were also 
Table 1 Maternal characteristics, neonatal characteristics and obstetric practice factors of spontaneous vaginal delivery, assisted vaginal delivery and caesarean delivery (with and without labour) deliveries at term, in Nova Scotia, 1988-2002

\begin{tabular}{|c|c|c|c|c|}
\hline Characteristics & $\begin{array}{l}\text { Spontaneous vaginal } \\
\text { delivery } \\
\text { ( } n=99679)\end{array}$ & $\begin{array}{l}\text { Assisted vaginal } \\
\text { delivery } \\
\text { ( }=15987)\end{array}$ & $\begin{array}{l}\text { Caesarean in } \\
\text { labour } \\
(n=16508)\end{array}$ & $\begin{array}{l}\text { Caesarean without } \\
\text { labour } \\
\text { ( } n=10755)\end{array}$ \\
\hline \multicolumn{5}{|l|}{ Maternal } \\
\hline Nulliparous (\%) & $36848(37.0)$ & $12071(75.5)$ & $11331(68.6)$ & $2344(21.8)$ \\
\hline Smoking (\%) & $28720(29.7)$ & $3945(25.4)$ & $4239(26.4)$ & $2844(27.1)$ \\
\hline Maternal weight at delivery $(\mathrm{kg})$, mean (SD) & $79.5(14.1)$ & $79.7(14.1)$ & $84.3(16.5)$ & $83.4(16.7)$ \\
\hline Gestational hypertension (\%) & $7298(7.3)$ & $2018(12.6)$ & $2501(15.2)$ & $839(7.8)$ \\
\hline Gestational diabetes (\%) & $2010(2.0)$ & $366(2.3)$ & $655(4.0)$ & $424(3.9)$ \\
\hline Regional anaesthesia (\%) & $26351(26.4)$ & $9605(60.1)$ & 12461 (75.5) & 8376 (77.9) \\
\hline Induced labour (\%) & $18751(18.8)$ & $4100(25.6)$ & $5660(34.3)$ & $0(0.0)$ \\
\hline \multicolumn{5}{|l|}{ Neonatal } \\
\hline
\end{tabular}

LGA, large for gestational age; SD, standard deviation; SGA, small for gestational age.

included for the study population after 1 January 1996, when they became consistently coded in the database.

Adverse neonatal outcomes were compared between methods of delivery. For initial analysis, all caesarean deliveries were compared with spontaneous vaginal deliveries and assisted vaginal deliveries. Assisted vaginal deliveries included the use of forceps or vacuum extraction, or both. In subsequent analyses, we divided the caesarean deliveries into two groups: those performed in labour and those without labour. Neonatal outcomes in both of these groups were independently compared with neonatal outcomes of spontaneous vaginal delivery and neonatal outcomes of assisted vaginal delivery. In all analyses, the vaginal delivery group was assigned as the referent group.

Categorical data were compared using $\chi^{2}$ analysis, while continuous variables were compared using the Student $t$ test. To isolate the effect of method of delivery on neonatal outcome, we used logistic regression to control for possible confounders based on clinical understanding, including the influence of maternal characteristics, pre-existing maternal conditions, obstetric practice factors and fetal characteristics. Maternal characteristics included maternal age $\geqslant 35$ years, parity, smoking, maternal weight at delivery and previous caesarean delivery. Pre-existing maternal conditions considered included chronic hypertensive disease and pre-existing diabetes, and conditions complicating pregnancy included gestational hypertension (eclampsia, pregnancy-induced hypertension and/or HELLP syndrome) and gestational diabetes. Obstetric practice factors included were induction of labour, use of regional anaesthesia, and type of delivery hospital. The type of delivery hospital was classified as tertiary (those providing obstetric and comprehensive perinatal intensive care), regional (those providing care for moderately complicated neonatal and obstetric cases, including operative delivery); and community (those providing low-risk obstetric services and organised referral for

Table 2 Rates of selected neonatal outcomes of term infants delivered by spontaneous vaginal delivery, assisted vaginal delivery and caesarean delivery with and without labour, in Nova Scotia, 1988-2002

\begin{tabular}{|c|c|c|c|c|}
\hline Neonatal outcomes & $\begin{array}{l}\text { Spontaneous } \\
\text { vaginal delivery }(\%) \\
(\mathrm{n}=99679)\end{array}$ & $\begin{array}{l}\text { Assisted vaginal } \\
\text { delivery }(\%) \\
(\mathrm{n}=15987)\end{array}$ & $\begin{array}{l}\text { Caesarean in } \\
\text { labour }(\%) \\
(n=16508)\end{array}$ & $\begin{array}{l}\text { Caesarean without } \\
\text { labour (\%) } \\
(\mathrm{n}=10 \mathrm{755})\end{array}$ \\
\hline \multicolumn{5}{|l|}{ Depression at birth } \\
\hline $\begin{array}{l}\text { Delay in initiating and maintaining } \\
\text { respiration }\end{array}$ & $367(0.4)$ & $150(0.9)$ & $287(1.7)$ & $41(0.4)$ \\
\hline Low 5-minute Apgar $(\leqslant 3)$ & $79(0.1)$ & $28(0.2)$ & $53(0.3)$ & $15(0.1)$ \\
\hline HIE and associated sequelae & $86(0.1)$ & $48(0.3)$ & $77(0.5)$ & $13(0.1)$ \\
\hline \multicolumn{5}{|l|}{ Neonatal birth trauma } \\
\hline Minor trauma & $1099(1.1)$ & $774(4.8)$ & $194(1.2)$ & $6(0.1)$ \\
\hline Major trauma & $311(0.3)$ & $225(1.4)$ & $25(0.2)$ & $7(0.1)$ \\
\hline \multicolumn{5}{|l|}{ Respiratory conditions } \\
\hline RDS & $78(0.1)$ & $19(0.1)$ & $25(0.2)$ & $67(0.6)$ \\
\hline Transient tachypnoea & $644(0.6)$ & $116(0.7)$ & $190(1.2)$ & $168(1.6)$ \\
\hline Aspiration pneumonitis & $268(0.3)$ & $69(0.4)$ & $119(0.7)$ & $26(0.2)$ \\
\hline NICU stay $>24$ hours & $2155(2.2)$ & $572(3.6)$ & $859(5.2)$ & $474(4.4)$ \\
\hline Breast feeding at discharge & $58588(59.1)$ & $9524(60.1)$ & $9744(59.5)$ & $5828(54.6)$ \\
\hline
\end{tabular}

HIE, hypoxic-ischaemic encephalopathy; NICU, neonatal intensive care unit; RDS, respiratory distress syndrome. 
high-risk maternal and neonatal cases). Newborn characteristics included year of birth, gestational age, small for gestational age $(<10$ th centile birth weight for gestational age) and large for gestational age ( $>90$ th centile birth weight for gestational age). Logistic regression employing the method of general estimating equations (GEE) generated standard errors that accounted for the non-independence of separate pregnancies to the same woman. Statistical significance was $p<0.05$. Statistical analyses were performed using the SPSS programming package for Windows (version 11.5) and Epilnfo (CDC, Atlanta, Georgia, USA).

\section{RESULTS}

A total of 142971 neonates satisfied inclusion and exclusion criteria from a potential study population of 147100 newborns, 27263 (19\%) of which were delivered by caesarean delivery. There were one and a half times as many caesarean deliveries in labour as without labour, and six times as many spontaneous vaginal deliveries as assisted vaginal deliveries. The main indications for caesarean delivery in labour were dystocia (59.0\%) and fetal distress (19.2\%). Caesarean deliveries without labour were performed primarily because of previous caesarean delivery (62.1\%) and breech presentation (22.1\%).

Table 1 summarises maternal characteristics, neonatal characteristics and obstetric practice factors. Mothers delivered by caesarean were more likely to be nulliparous $(50.2 \%, \mathrm{p}<0.001)$, $\geqslant 35$ years $(12.8 \%, \mathrm{p}<0.001)$ and have higher mean weight at delivery $(83.9 \mathrm{~kg}, \mathrm{p}<0.001)$ than those who had a spontaneous vaginal delivery $(37.0 \%, 8.9 \%$ and $79.5 \mathrm{~kg}$, respectively), but were less likely to have smoked $(26.7 \%$ vs $29.7 \%, p<0.001)$. They were more likely to have pre-existing hypertension $(1.4 \%$, $\mathrm{p}<0.001)$, pre-existing diabetes $(0.6 \%, \mathrm{p}<0.001)$, or gestational hypertension $(12.3 \%, \mathrm{p}<0.001)$ or gestational diabetes $(4.0 \%$, $\mathrm{p}<0.001)$ than those having a spontaneous vaginal delivery $(0.6 \%, 0.1 \%, 7.3 \%$ and $2.0 \%$, respectively). Women undergoing caesarean delivery were more likely to have infants large for gestational age $(18.7 \%, \mathrm{p}<0.001)$ of earlier gestational age
(39.4 weeks, $p<0.001$ ) than those undergoing spontaneous vaginal delivery (11.8\% and 39.7 weeks, respectively). Within the caesarean delivery group, women undergoing caesarean without labour were less likely to be nulliparous $(21.8 \%$, $\mathrm{p}<0.001)$ and their neonates were delivered at an earlier gestational age $(38.9$ weeks, $\mathrm{p}<0.001)$ than those who underwent caesarean in labour (68.6\% and 39.8 weeks, respectively).

Table 2 shows rates of neonatal outcomes between methods of delivery. With the exception of NICU admissions across all groups (range $2.2 \%-5.2 \%$ ), and cephalohaematoma specifically in the babies delivered by assisted vaginal delivery (4.8\%), the rates of all neonatal outcomes were approximately $1 \%$.

Initially, neonatal outcomes were compared between infants delivered by caesarean as a whole group (including both caesarean with and without labour) and by spontaneous and assisted vaginal delivery (data not shown). Significant differences were seen in the rates of all outcomes of infants delivered by caesarean in comparison with those delivered by spontaneous vaginal delivery $(p<0.001)$ in both unadjusted and adjusted comparisons. No significant differences were found in the rates of aspiration pneumonitis, low 5-minute Apgar score, or hypoxic-ischaemic encephalopathy (HIE) and associated sequelae in babies delivered by caesarean compared with the assisted vaginal delivery group, after adjustment for confounding variables.

Tables 3-6 summarise the crude univariate and adjusted multivariate comparisons of neonatal outcomes between the caesarean delivery groups, categorised as caesarean deliveries performed with labour and without labour, and the vaginal delivery groups, categorised as spontaneous or assisted. Table 3 demonstrates comparisons of neonatal outcomes between caesarean delivery in labour and spontaneous vaginal delivery. Neonatal outcomes following caesarean delivery in labour showed a four- to fivefold increase in risk for depression at birth and a two- to threefold increase in risk of all neonatal respiratory conditions $(p<0.01)$. Neonates delivered by caesarean in labour showed a $66 \%$ reduction in risk of major trauma

Table 3 Comparison of rates of selected neonatal outcomes among infants delivered at term by caesarean section in labour and by spontaneous vaginal delivery, in Nova Scotia, 1988-2002

\begin{tabular}{|c|c|c|c|c|}
\hline \multirow[b]{2}{*}{ Neonatal outcomes } & \multicolumn{2}{|l|}{ Crude } & \multicolumn{2}{|l|}{ Adjusted* } \\
\hline & OR (95\% CI) & p Value & OR (95\% CI) & p Value \\
\hline \multicolumn{5}{|l|}{ Depression at birth } \\
\hline $\begin{array}{l}\text { Delay in initiating and maintaining } \\
\text { respiration }\end{array}$ & 4.74 (4.06 to 5.52$)$ & $<0.001$ & 4.51 (3.70 to 5.51$)$ & $<0.001$ \\
\hline Low 5-minute Apgar score $(\leqslant 3)$ & $4.05(2.86$ to 5.74$)$ & $<0.001$ & $3.39(2.14$ to 5.36$)$ & $<0.001$ \\
\hline HIE and associated sequelae & 5.41 (3.98 to 7.35$)$ & $<0.001$ & $3.36(2.29$ to 4.93$)$ & $<0.001$ \\
\hline \multicolumn{5}{|l|}{ Neonatal birth trauma } \\
\hline Minor trauma & $1.08(0.93$ to 1.25$)$ & 0.34 & $0.80(0.67$ to 0.95$)$ & 0.01 \\
\hline Major trauma & $0.49(0.32$ to 0.73$)$ & $<0.001$ & $0.34(0.21$ to 0.56$)$ & $<0.001$ \\
\hline \multicolumn{5}{|l|}{ Respiratory conditions } \\
\hline RDS & $1.94(1.23$ to 3.04$)$ & 0.005 & $2.08(1.23$ to 3.54$)$ & 0.01 \\
\hline Transient tachypnoea & $1.78(1.52$ to 2.09$)$ & $<0.001$ & 1.99 (1.63 to 2.44$)$ & $<0.001$ \\
\hline Aspiration pneumonitis & $2.68(2.16$ to 3.33$)$ & $<0.001$ & 2.18 (1.66 to 2.87$)$ & $<0.001$ \\
\hline NICU stay $>24$ hours & $2.41(2.23$ to 2.60$)$ & $<0.001$ & 1.66 (1.50 to 1.84$)$ & $<0.001$ \\
\hline Breastfeeding at discharge & $1.01(0.99$ to 1.02$)$ & 0.34 & $0.79(0.77$ to 0.83$)$ & $<0.001$ \\
\hline
\end{tabular}

*Adjusted for year of delivery, maternal age, parity, smoking, maternal weight at delivery, hypertensive disease, diabetes, previous caesarean delivery, the use of regional anaesthesia, the induction of labour, gestational age, and large and small for gestational age, where significant.

HIE, hypoxic-ischaemic encephalopathy; NICU, neonatal intensive care unit; RDS, respiratory distress syndrome. 
Table 4 Comparison of rates of selected neonatal outcomes among infants delivered at term by caesarean section without labour and by spontaneous vaginal delivery in Nova Scotia, 1988-2002

\begin{tabular}{|c|c|c|c|c|}
\hline \multirow[b]{2}{*}{ Neonatal outcomes } & \multicolumn{2}{|l|}{ Crude } & \multicolumn{2}{|l|}{ Adjusted* } \\
\hline & OR (95\% CI) & p Value & OR $(95 \% \mathrm{CI})$ & p Value \\
\hline \multicolumn{5}{|l|}{ Depression at birth } \\
\hline Delay in initiating and maintaining respiration & $1.04(0.75$ to 1.43$)$ & 0.89 & $1.21(0.80$ to 1.84$)$ & 0.37 \\
\hline Low 5-minute Apgar score $(\leqslant 3)$ & $1.76(1.01$ to 3.06$)$ & 0.06 & $3.33(1.64$ to 6.78$)$ & $<0.001$ \\
\hline HIE and associated sequelae & $1.40(0.78$ to 2.51$)$ & 0.33 & $1.68(0.84$ to 3.35$)$ & 0.14 \\
\hline \multicolumn{5}{|l|}{ Neonatal birth trauma } \\
\hline Minor trauma & $0.12(0.07$ to 0.20$)$ & $<0.001$ & $0.09(0.05$ to 0.17$)$ & $<0.001$ \\
\hline Major trauma & $0.21(0.10$ to 0.44$)$ & $<0.001$ & $0.20(0.08$ to 0.52$)$ & $<0.001$ \\
\hline \multicolumn{5}{|l|}{ Respiratory conditions } \\
\hline RDS & $7.96(5.75$ to 11.03$)$ & $<0.001$ & 5.39 (3.24 to 8.98$)$ & $<0.001$ \\
\hline Transient tachypnoea & $2.42(2.04$ to 2.86$)$ & $<0.001$ & $2.41(1.87$ to 3.10$)$ & $<0.001$ \\
\hline Aspiration pneumonitis & $0.90(0.60$ to 1.34$)$ & 0.67 & $1.11(0.66$ to 1.84$)$ & 0.50 \\
\hline NICU stay $>24$ hours & $2.04(1.85$ to 2.25$)$ & $<0.001$ & $1.33(1.16$ to 1.54$)$ & $<0.001$ \\
\hline Breastfeeding at discharge & $0.92(0.91$ to 0.94$)$ & $<0.001$ & $0.64(0.60$ to 0.67$)$ & $<0.001$ \\
\hline
\end{tabular}

\footnotetext{
${ }^{*}$ Adjusted for year of delivery, maternal age, parity, smoking, maternal weight at delivery, hypertensive disease, diabetes, previous caesarean delivery, the use of regional anaesthesia, the induction of labour, gestational age, and large and small for gestational age, where significant.

HIE, hypoxic-ischaemic encephalopathy; NICU, neonatal intensive care unit; RDS, respiratory distress syndrome.
}

$(95 \%$ CI 0.21 to $0.56, \mathrm{p}<0.001)$ and a $20 \%$ reduction in risk of minor trauma $(95 \%$ CI 0.67 to $0.95, \mathrm{p}<0.001)$ compared with spontaneous vaginal delivery.

Table 4 summarises comparisons of neonatal outcomes between caesarean delivery without labour and spontaneous vaginal delivery. Neonates delivered by caesarean delivery without labour had a threefold increased risk of having a low 5-minute Apgar score compared with those delivered by spontaneous vaginal delivery (95\% CI 1.64 to $6.78, \mathrm{p}<0.001)$, although there was no difference in the outcomes of delay in initiating or maintaining respiration, or HIE and associated sequelae. Neonates delivered by caesarean delivery without labour were $91 \%$ (95\% CI 0.05 to $0.17, \mathrm{p}<0.001)$, and $80 \%(95 \%$ CI 0.08 to $0.52, p<0.001)$ less likely to have a complication of minor and major trauma, respectively, compared with spontaneous vaginal delivery. With the exception of aspiration pneumonitis, the respiratory conditions of RDS and TTN remained significantly more likely in the caesarean delivery without labour group ( $O R=5.39,95 \%$ CI 3.24 to 8.98, $p<0.001$ and $\mathrm{OR}=2.41,95 \%$ CI 1.87 to $3.10, \mathrm{p}<0.001$, respectively).

Table 5 summarises comparisons of neonatal outcomes between caesarean delivery in labour and assisted vaginal delivery. Neonatal outcomes following caesarean in labour showed a one- to twofold increase in risk for depression at birth and all neonatal respiratory conditions $(p<0.01)$, except RDS $(\mathrm{OR}=1.24,95 \%$ CI 0.66 to $2.34, \mathrm{p}=0.51)$, compared with infants following assisted vaginal delivery. Neonates delivered by caesarean in labour showed a $75 \%$ reduction in risk of minor

Table 5 Comparison of rates of selected neonatal outcomes among infants delivered at term by caesarean section in labour and by assisted vaginal delivery in Nova Scotia, 1988-2002

\begin{tabular}{|c|c|c|c|c|}
\hline \multirow[b]{2}{*}{ Neonatal outcomes } & \multicolumn{2}{|l|}{ Crude } & \multicolumn{2}{|l|}{ Adjusted* } \\
\hline & OR (95\% Cl) & p Value & OR (95\% CI) & p Value \\
\hline \multicolumn{5}{|l|}{ Depression at birth } \\
\hline Delay in initiating and maintaining respiration & $1.85(1.52$ to 2.26$)$ & $<0.001$ & $2.09(1.66$ to 2.61$)$ & $<0.001$ \\
\hline Low 5-minute Apgar score $(\leqslant 3)$ & $1.84(1.16$ to 2.90$)$ & 0.01 & $2.13(1.24$ to 3.65$)$ & 0.006 \\
\hline HIE and associated sequelae & 1.55 (1.08 to 2.23$)$ & 0.02 & $1.63(1.08$ to 2.45$)$ & 0.02 \\
\hline \multicolumn{5}{|l|}{ Neonatal birth trauma } \\
\hline Minor trauma & $0.25(0.21$ to 0.29$)$ & $<0.001$ & $0.25(0.21$ to 0.29$)$ & $<0.001$ \\
\hline Major trauma & $0.11(0.07$ to 0.16$)$ & $<0.001$ & $0.07(0.04$ to 0.11$)$ & $<0.001$ \\
\hline \multicolumn{5}{|l|}{ Respiratory conditions } \\
\hline RDS & $1.27(0.70$ to 2.31$)$ & 0.52 & $1.24(0.66$ to 2.34$)$ & 0.51 \\
\hline Transient tachypnoea & 1.59 (1.26 to 2.00$)$ & $<0.001$ & $1.48(1.15$ to 1.90$)$ & 0.002 \\
\hline Aspiration pneumonitis & $1.67(1.24$ to 2.25$)$ & $<0.001$ & $1.62(1.17$ to 2.25$)$ & 0.004 \\
\hline NICU stay $>24$ hours & $1.45(1.31$ to 1.61$)$ & $<0.001$ & $1.24(1.10$ to 1.40$)$ & $<0.001$ \\
\hline Breastfeeding at discharge & $0.99(0.97$ to 1.01$)$ & 0.34 & $0.93(0.89$ to 0.98$)$ & 0.006 \\
\hline
\end{tabular}

\footnotetext{
${ }^{*}$ Adjusted for year of delivery, maternal age, parity, smoking, maternal weight at delivery, hypertensive disease, diabetes, previous caesarean delivery, the use of regional anaesthesia, the induction of labour, gestational age, and large and small for gestational age, where significant.

HIE, hypoxic-ischaemic encephalopathy; NICU, neonatal intensive care unit; RDS, respiratory distress syndrome.
} 
Table 6 Comparison of rates of selected neonatal outcomes among infants delivered at term by caesarean section without labour and by assisted vaginal delivery in Nova Scotia, 1988-2002

\begin{tabular}{|c|c|c|c|c|}
\hline \multirow[b]{2}{*}{ Neonatal outcomes } & \multicolumn{2}{|l|}{ Crude } & \multicolumn{2}{|l|}{ Adjusted* } \\
\hline & OR $(95 \% \mathrm{CI})$ & p Value & OR $(95 \% \mathrm{CI})$ & p Value \\
\hline \multicolumn{5}{|l|}{ Depression at birth } \\
\hline Delay in initiating and maintaining respiration & 0.41 (0.29 to 0.57$)$ & $<0.001$ & $0.56(0.36$ to 0.86$)$ & 0.01 \\
\hline Low 5-minute Apgar score $(\leqslant 3)$ & $0.80(0.43$ to 1.49$)$ & 0.58 & 2.09 (0.96 to 4.54$)$ & 0.06 \\
\hline HIE and associated sequelae & $0.40(0.22$ to 0.74$)$ & 0.004 & $0.81(0.40$ to 1.66$)$ & 0.57 \\
\hline \multicolumn{5}{|l|}{ Neonatal birth trauma } \\
\hline Minor trauma & $0.03(0.02$ to 0.05$)$ & $<0.001$ & $0.03(0.02$ to 0.05$)$ & $<0.001$ \\
\hline Major trauma & 0.05 (0.02 to 0.10$)$ & $<0.001$ & $0.04(0.02$ to 0.10$)$ & $<0.001$ \\
\hline \multicolumn{5}{|l|}{ Respiratory conditions } \\
\hline RDS & 5.24 (3.15 to 8.72$)$ & $<0.001$ & $3.21(1.71$ to 6.01$)$ & $<0.001$ \\
\hline Transient tachypnoea & 2.15 (1.70 to 2.72$)$ & $<0.001$ & 1.78 (1.33 to 2.40$)$ & $<0.001$ \\
\hline Aspiration pneumonitis & 0.56 (0.36 to 0.88$)$ & 0.01 & 0.82 (0.48 to 1.42$)$ & 0.50 \\
\hline NICU stay $>24$ hours & $1.23(1.09$ to 1.39$)$ & $<0.001$ & $1.00(0.85$ to 1.17$)$ & 0.99 \\
\hline Breast feeding at discharge & 0.91 (0.89 to 0.93 ) & $<0.001$ & $0.74(0.70$ to 0.79$)$ & $<0.001$ \\
\hline
\end{tabular}

\footnotetext{
${ }^{*}$ Adjusted for year of delivery, maternal age, parity, smoking, maternal weight at delivery, hypertensive disease, diabetes, previous caesarean delivery, the use of regional anaesthesia, the induction of labour, gestational age, and large and small for gestational age, where significant.

HIE, hypoxic-ischaemic encephalopathy; NICU, neonatal intensive care unit; RDS, respiratory distress syndrome.
}

trauma (95\% CI 0.21 to $0.29, \mathrm{p}<0.001)$ and a $93 \%$ reduction in risk of major trauma (95\% CI 0.04 to $0.11, \mathrm{p}<0.001)$, compared with assisted vaginal delivery.

Table 6 summarises comparisons of neonatal outcomes between caesarean delivery without labour and assisted vaginal delivery. Infants delivered by caesarean without labour were $44 \%$ less likely to have delay in initiating and maintaining respiration ( $95 \%$ CI 0.36 to $0.86, p=0.01$ ), but had a 3.2 -fold increased risk of RDS (95\% CI 1.71 to $6.01, p<0.001)$ and a 1.8fold increased risk of TTN (95\% CI 1.33 to $2.40, \mathrm{p}<0.001$ ), compared with infants delivered by assisted vaginal delivery. Infants delivered by caesarean without labour were $97 \%$ less likely to have complications of minor trauma (95\% CI 0.02 to $0.05, p<0.001)$, and $96 \%$ less likely to have major trauma $(95 \%$ CI 0.02 to $0.10, p<0.001)$, compared with infants delivered by assisted vaginal delivery. No differences were seen in the rates of aspiration pneumonitis, low 5-minute Apgar scores, or HIE and associated sequelae.

The outcome of NICU stay for longer than 24 hours was significantly more likely for all infants in any caesarean delivery group compared with any vaginal group $(p<0.001)$, except when caesarean without labour was compared with assisted vaginal delivery. The proportion of women breast feeding at discharge from hospital $(p<0.01)$ was consistently less likely in any caesarean delivery group than in any vaginal group with adjusted analyses.

Data for umbilical cord pHs was available only from 1996 onwards. However, the incidence of both a cord $\mathrm{pH}<7$ and a base excess $<-15$ occurring together was low $(<1 \%)$, and was significantly less likely with infants born by caesarean with labour $(0.9 \%)$ or without labour $(1.0 \%)$ than with spontaneous vaginal delivery $(0.3 \%, \mathrm{p}<0.001$ and $\mathrm{p}<0.001$, respectively) but not for assisted vaginal delivery $(0.6 \%, p=0.37$ and $p=0.53$, respectively).

Missing values for some variables constituted $14 \%$ of the population ( $85 \%$ were weight at delivery); these values were not included in the regression analysis. When the cases were divided into a group who had a value for weight at delivery and a group who did not and compared by the rates of individual outcomes, the two groups were virtually indistinguishable.

\section{DISCUSSION}

This population-based study examined a general population that included both low- and high-risk pregnant women. Regression analyses allowed evaluation of the effect of method of delivery at term in these women on three clinically significant neonatal outcomes-namely, depression at birth, neonatal trauma and neonatal respiratory complications. Rates of caesarean delivery in our study population (19\%) reflect rates seen in the United States $(21 \%)^{2}$ and elsewhere in Canada (20\%). ${ }^{1}$

Respiratory morbidity has received the greatest attention in the evaluation of neonatal outcomes by method of delivery. Risk factor analyses have suggested that caesarean delivery is an independent predictive factor for $\operatorname{RDS}(\mathrm{OR}=2.3$ for caesarean delivery, especially for caesarean without labour $(\mathrm{OR}=2.6) .{ }^{15}$ Outcomes analyses (examining women with previous caesarean delivery) report increased risks of $\mathrm{RDS}^{13}{ }^{17}$ and other measures of neonatal respiratory morbidity. ${ }^{72} 13$ Our study demonstrated very low rates $(<1 \%)$ of significant neonatal respiratory complications such as RDS and aspiration pneumonitis following any method of delivery, which is consistent with most recent studies ${ }^{12} 13151720$ but lower than others, ${ }^{11}{ }^{19}$ and may be explained by the large population-based cohort examined in our study.

Previous studies have suggested that the respiratory morbidity seen with caesarean delivery, specifically caesarean without labour, may be due in part to delivery thought to be term but delivered early as a result of uncertain dates, ${ }^{25}$ and this conclusion is supported by evidence of decreasing risk of respiratory morbidity with increasing gestational age. ${ }^{11}$ In Nova Scotia, access to universal healthcare ensures at least a screening ultrasound throughout the province at 18-20 weeks' gestational age, which also allows for confirmation of dates. Gestational age certainty, with delivery at term, supports the finding of low rates of respiratory morbidity in our study. 


\section{What is already known on this topic}

- Caesarean delivery rates are rising, owing in part to changing maternal characteristics and obstetric practice patterns.

- Neonatal outcomes associated with method of delivery have focused on increased respiratory morbidity and may have been influenced by gestational age at delivery.

- These studies have been limited by observations in specific populations and small numbers.

Additionally, caesarean delivery without labour is typically performed at or later than 39 weeks' gestational age, ${ }^{26}$ and in more than half of the provincial deliveries (which occur at the tertiary maternity hospital, the IWK Health Centre) caesarean delivery without labour and before 39 weeks' gestational age was preceded by amniocentesis to confirm fetal lung maturity. No clinically significant difference in gestational age at delivery was found in the different methods of delivery in our study. The two- to sixfold increase in risk of significant neonatal respiratory complications for caesarean delivery with labour and without labour compared with spontaneous and assisted vaginal delivery are arguably not of clinical significance considering our observed low rates of respiratory conditions.

The size of our study population allowed the evaluation of the rare outcomes of delay in initiating and maintaining respiration, low 5-minute Apgar score, and HIE and associated sequelae, all of which, except for delay in initiating and maintaining respiration with caesarean delivery in labour $(1.7 \%)$, had rates $<1 \%$. Rates of HIE and associated sequelae were less than those of delay in initiating and maintaining respiration, emphasising the transient nature of respiratory compromise seen at birth in our population. Interestingly, caesarean delivery in labour was more likely to be associated with increased risks of depression at birth outcomes compared with spontaneous and assisted vaginal delivery than caesarean delivery without labour, and this finding may represent outcomes associated with the indication for caesarean delivery in labour as opposed to the method of delivery itself. Risk factor analysis evaluating a similar population supports the significant relationship between operative delivery in labour and depression at birth. ${ }^{14}$ Other studies have evaluated surrogate measures of depression (such as umbilical cord arterial $\mathrm{pH}$ ) at birth by method of delivery in select populations and these show low rates of adverse outcome and increased risk in caesarean delivery without labour, ${ }^{13}$ consistent with our study.

Caesarean delivery has been shown to be protective against neonatal trauma in comparison with vaginal delivery when operative delivery is required in the second stage of labour. ${ }^{71}$ Our study demonstrated a striking reduction in risk of significant neonatal trauma with caesarean delivery compared with vaginal delivery, especially when type of labour was considered. In particular, caesarean delivery without labour was associated with a $66 \%$ and a $97 \%$ reduction in significant neonatal trauma compared with spontaneous vaginal delivery and assisted vaginal delivery, respectively, in a general population.

NICU stay greater than 24 hours was employed as an approximation of significant neonatal complications and to minimise admissions for short-term observation. Our findings of increased rates of NICU admission for neonates delivered by caesarean delivery compared with those delivered vaginally are consistent with other reports that have shown similar NICU

\section{What this study adds}

- This is a large population-based cohort study $(n=142929)$.

- The results are applicable to a general population with data on both low- and high-risk pregnant women.

- The study provides useful information not only on neonatal respiratory complications but also on depression at birth and neonatal trauma.

needs for both emergent and elective deliveries. ${ }^{12}{ }^{27}$ Previous reports have demonstrated a negative association between caesarean delivery and breast feeding, ${ }^{28}$ consistent with our finding that women who delivered by caesarean delivery were less likely to be breast feeding at the time of discharge than those who delivered vaginally. Although caesarean delivery has been shown to delay the onset of breast feeding, ${ }^{29-31}$ recent reports have shown that this delay has no impact on the incidence of breast feeding several months post partum. ${ }^{30}{ }^{31}$

This study did not attempt to examine long = term pulmonary, neurological or traumatic consequences of the method of delivery. There may have been variables that affected relationships between methods of delivery that were not available in the database. Although this retrospective study used data from the Nova Scotia Atlee Perinatal Database, the information database is known to be reliable and of high quality based on routine data checks and edits made at the time of data collection by qualified health records personnel, and validation ${ }^{32}{ }^{33}$ and reabstraction studies which attest to the quality of the data in the database.

Increasing attention is being given to outcomes associated with method of delivery in light of changing maternal and neonatal characteristics and obstetric practice patterns, including the option of caesarean delivery by maternal request in the absence of complications. This population-based study of neonatal morbidity in a general obstetric cohort demonstrated significant increases in risk of birth depression and neonatal respiratory complications with caesarean delivery compared with vaginal delivery; however, in our study the rates of these outcomes were low across all categories. Significant neonatal trauma was reduced with caesarean delivery, particularly with caesarean delivery without labour. While the increased risks of outcomes with caesarean delivery are consistently limited to caesarean in labour and risks of trauma are notably decreased with caesarean without labour, women and their families in a similar population planning a pregnancy may be assured that the rates of adverse neonatal outcomes are low. The rate of emergency/urgent caesarean delivery in any group planning a vaginal delivery may provide additional information about infant health for a woman and her family.

Acknowledgements: We thank the Reproductive Care Program of Nova Scotia for facilitating access to the data and the IWK Health Centre and Dalhousie University for providing summer research student funding (FL). VMA is supported by a Clinical Research Scholar Award from Dalhousie University and by a New Investigator Award of the Canadian Institutes of Health Research.

Competing interests: None.

Ethics approval: Ethical approval was obtained from the research ethics board at the IWK Health Centre in Halifax, Nova Scotia.

\section{REFERENCES}

1. Health Canada. Canadian Perinatal Health Report, 2003. Ottawa: Minister of Public Works and Government Services Canada, 2003. 
2. Martin JA, Hamilton BE, Ventura SJ, et al. Births: final data for 2000. Natl Vital Stat Rep 2002;50:1-101.

3. Dobson R. Caesarean section rate in England and Wales hits $21 \%$. BMJ 2001;323:951.

4. Joseph KS, Young DC, Dodds L, et al. Changes in maternal characteristics and obstetric practice and recent increases in primary cesarean delivery. Obstet Gynecol 2003;102:791-800.

5. Bewley S, Cockburn J. The unethics of 'request' cesarean section. BJOG 220;109:593-6.

6. Bewley S, Cockburn J. The unfacts of 'request' cesarean section. BJOG 220;109:597-605.

7. Murphy DJ, Liebling RE, Verity L, et al. Early maternal and neonatal morbidity associated with operative delivery in second stage of labour: a cohort study. Lancet 2001;358:1203-7.

8. Allen VM, O'Connell CM, Liston RM, et al. Maternal morbidity associated with cesarean delivery without labor compared with spontaneous onset of labor at term. Obstet Gynecol 2003;102:477-82.

9. Allen VM, O'Connell CM, Baskett TF. Maternal and perinatal morbidity of caesarean delivery at full cervical dilatation compared with caesarean delivery in the first stage of labor. BJOG 2005;112:986-90.

10. Allen VM, O'Connell CM, Baskett TF. Maternal morbidity associated with cesarean delivery without labor compared with induction of labor at term. Obstet Gynecol 2006;108:286-94.

11. Morrison JJ, Rennie JM, Milton PJ. Neonatal respiratory morbidity and mode of delivery at term: influence of timing of elective caesarean section. $\mathrm{Br} \mathrm{J}$ Obstet Gynaecol 1995;102:101-6.

12. Fogelson NS, Mernard MK, Hulsey T, et al. Neonatal impact of elective repeat cesarean delivery at term: a comment on patient choice cesarean delivery. Am J Obstet Gynecol 2005:192;1433-6.

13. Richardson BS, Czikk MJ, daSilva 0 , et al. The impact of labour at term on measures of neonatal outcome. Am J Obstet Gynecol 2005;192:219-26.

14. Baskett TF, Allen VM, O'Connell CM, et al. Predictors of respiratory depression at birth in the term infant. BJOG 2006;113:769-74.

15. Gerten KA, Coonrod DV, Bay RC, et al. Cesarean delivery and respiratory distress syndrome: does labor make a difference? Am J Obstet Gynecol 2005;193:1061-4.

16. Wax JR, Hersen V, Carignan $\mathrm{E}$, et al. Contribution of elective delivery to severe respirator distress at term. Am J Perinatol 2002;19:81-6.

17. Levine EM, Ghai $\mathrm{V}$, Barton JJ, et al. Mode of delivery and risk of respiratory diseases in newborns. Obstet Gynecol 2001;97:439-42.
18. Zanardo V, Simbi AK, Franzoi M, et al. Neonatal respiratory morbidity risk and mode of delivery at term: influence of timing of elective caesarean delivery. Acta Paediatr 2004; 93:643-7.

19. Hook B, Kiwi R, Amini SB, et al. Neonatal morbidity after repeat elective cesarean section and trial of labor. Pediatrics 1997;100:348-53.

20. Many A, Helpman L, Vilnai $Y$, et al. Neonatal respiratory morbidity after elective cesarean section. J Matern Fetal Neonatal Med 2006;19:75-8.

21. Towner D, Castro MA, Eby-Wilkens $E$, et al. Effect of mode of delivery in nulliparous women on neonatal intracranial injury. N Engl J Med 1999;341:1709-14.

22. Allen AC, Attenborough R, Dodds L, et al. Perinatal care in Nova Scotia, 1988-1995 Report from the Nova Scotia Atlee Perinatal Database, Halifax (Canada): the Reproductive Care Program of Nova Scotia, 1996.

23. Statistics Canada. 2001 Census Nation Tables. http://www40.statcan.ca/101/ cst01/demo26d.htm (accessed 9 December 2007).

24. Sarnat HB, Sarnat S. Neonatal encephalopathy following fetal distress. A clinical and electroencephalographic study. Arch Neurol 1976;33:696-705.

25. Bowers SK, MacDonald HM, Shapiro ED. Prevention of iatrogenic neonatal respiratory distress syndrome: elective repeat cesarean section and spontaneous labor. Am J Obstet Gynecol 1982;143:186-9.

26. Anonymous. ACOG Education Bulletin. Assessment of fetal lung maturity. Int J Gynaecol Obstet 1997;56:191-8.

27. Annibale DJ, Hulsey TC, Wagner CL, et al. Comparative neonatal morbidity of abdominal and vaginal deliveries after uncomplicated pregnancies. Arch Pediatr Adolesc Med 1995;149:862-7.

28. Perez-Escamilia R, Maulen-Randovan I, Dewey KG. The association between cesarean delivery and breast-feeding outcomes among Mexican women. Am J Public Health 1996;86:832-6.

29. Dewey KG, Nommsen-Rivers LA, Heinig MJ, et al. Risk factors for suboptimal infant breastfeeding behavior, delayed onset of lactation, and excess neonatal weight loss. Pediatrics 2003;112:607-19.

30. Rowe-Murray HJ, Fisher JR. Baby friendly hospital practices: cesarean section is a persistent barrier to early initiation of breastfeeding. Birth 2002;29:124-31.

31. Hannah ME, Hannah WJ, Hodnett ED, et al. Outcomes at 3 months after planned cesarean vs planned vaginal delivery for breech presentation at term: the international randomized Term Breech Trial. JAMA 2002;287:1822-31.

32. Fair M, Cyr M, Allen AC, et al. An assessment of the validity of a computer system probabilistic record linkage of birth and infant death records in Canada. Chronic Dis Can 2000;21:8-13.

33. Fair M, Cyr M, Allen AC, et al. Validation study for a record linkage of births and infant deaths in Canada. Catalogue No. 84F0013XIE. Ottawa: Statistics Canada, 1999. 